\title{
Studi Deskriptif tentang Partisipasi dan Persepsi Mahasiswa terhadap Kegiatan Inaugurasi
}

Nesyana Nurmadilla1,*, Andi Anita Nur Fadhilah'1, Dwi Anggita1, Shulhana Mokhtar', Rasfayanah $^{1}$, Nasrudin Andi Mappaware ${ }^{1}$, Syamsu Rijal ${ }^{1}$

${ }^{1}$ Program Studi Pendidikan Dokter, Fakultas Kedokteran, Universitas Muslim Indonesia, Makassar, Indonesia

*Corresponding Author. E-mail: nesyananurmadilla@gmail.com, Mobile number: +62 811-4129-099

\begin{abstract}
ABSTRAK
Latar belakang:. Di semester 1, mahasiswa baru dihadapkan dengan jadwal perkuliahan yang padat dan persiapan kegiatan rutin tahunan inaugurasi yang cukup menyita waktu. Untuk memberikan gambaran tentang partisipasi dan persepsi mahasiswa terhadap kegiatan inaugurasi.

Metode: Penelitian ini merupakan studi deskriptif dengan menggunakan kuesioner yang telah divalidasi. Subjek penelitian adalah seluruh mahasiswa Fakulta Kedokteran Universitas Muslim Indonesia angkatan 2017 dan 2018 yang berpartisipasi pada kegiatan inaugurasi angkatannya dan terhitung masih aktif sebagai mahasiswa FK UMI saat penelitian berlangsung. Teknik pengumpulan sampel menggunakan total sampling.

Hasil: Mayoritas responden berpartisipasi sebagai panitia dan pengisi acara inaugurasi $(57,2 \%)$ dan menghabiskan 1-2 bulan untuk persiapan inaugurasi (51,69\%). Sebanyak 46,77\% responden menggunakan lebih dari 6 jam setiap hari untuk persiapan inaugurasi. Mayoritas responden berpendapat bahwa inaugurasi mengganggu konsentrasi belajar (80\%) dan menyebabkan waktu belajar berkurang (92\%) namun tetap perlu dilaksanakan $(80,3 \%)$.

Kesimpulan: Kegiatan inaugurasi cukup menyita waktu sehingga mengganggu konsentrasi dan waktu belajar namun perlu dilaksanakan.
\end{abstract}

Kata kunci: Persepsi mahasiswa; pengenalan mahasiswa baru; inaugurasi

Article history:

Received: 01 Mei 2020

Accepted: 23 Juni 2020

Published: 28 Desember2020

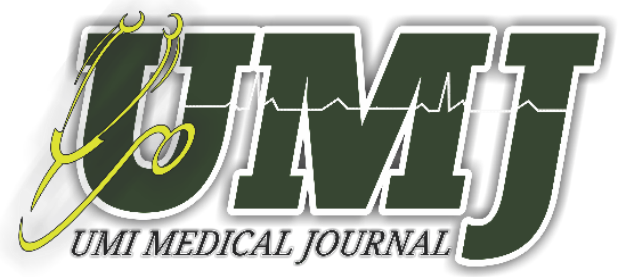

Published by :

Fakultas Kedokteran

Universitas Muslim Indonesia

Phone:

+6282293330002

\section{Address:}

Jl. Urip Sumoharjo Km. 5 (Kampus II UMI)

Makassar, Sulawesi Selatan.

Email:

medicaljournal@umi.ac.id 


\section{ABTRACT}

Background: In semester 1, new students are faced with a busy lecture schedule and time-consuming preparation for the annual inauguration activities. To provide an overview of student participation and perceptions of the inauguration activity.

Methods: This research is a descriptive study using a validated questionnaire. The research subjects were all students of the Faculty of Medicine at the Muslim University of Indonesia class of 2017 and 2018 who participated in the inauguration activity for their batch and were still active as FK UMI students during the research. The sample collection technique used total sampling.

Results: The majority of respondents participated as committee members and performers in the inauguration ceremony (57.2\%) and spent 1-2 months preparing for the inauguration (51.69\%). A total of $46.77 \%$ of respondents spent more than 6 hours each day in preparation for the inauguration. The majority of respondents thought that the inauguration interfered with learning concentration $(80 \%)$ and caused learning time to decrease $(92 \%)$ but it still needed to be implemented $(80.3 \%)$.

Conclusion: The inauguration activity was time-consuming so it could interfere with concentration and study time but it needs to be implemented.

Keywords: Student perceptions; introduction of new students; inauguration

\section{PENDAHULUAN}

Proses belajar mahasiswa di Fakultas Kedokteran Universitas Muslim Indonesia (FK UMI) dimulai pada semester satu dengan masa studi 20 minggu. Di semester satu ini, mahasiswa FK UMI akan mempelajari tiga mata kuliah blok dan empat mata kuliah dasar umum dengan total sks sebesar 23 SKS. ${ }^{1}$ Banyaknya topik perkuliahan yang tersaji menyebabkan jadwal kuliah menjadi padat mulai pukul delapan pagi hingga pukul lima sore. Agar dapat memperoleh hasil belajar yang memuaskan, seorang mahasiswa FK dituntut untuk mampu menyeimbangkan antara kegiatan akademik dengan kegiatan non akademik. ${ }^{2}$ Tidur yang cukup dan berkualitas adalah mutlak didapatkan agar fungsi kognitif seperti memori dan konsentrasi tidak terganggu. ${ }^{3}$

Sayangnya, di semester satu ini mahasiswa juga dihadapkan dengan kegiatan inaugurasi yang merupakan salah satu agenda rutin tahunan di FK UMI. Persiapan dan pelaksanaan inaugurasi ini terkesan sangat menyita waktu mahasiswa sehingga tidak jarang dosen mendapati mahasiswa tertidur di dalam kelas saat kuliah sementara berlangsung. Kegiatan inaugurasi ini jugalah yang ditengarai menjadi salah satu penyebab capaian hasil belajar mahasiswa pada beberapa blok di semester satu, tidak memuaskan. Meskipun demikian, mahasiswa baru tetap bersemangat untuk melaksanakan inaugrasi. Penelitian ini bertujuan untuk memberikan gambaran tentang partisipasi dan persepsi mahasiswa terhadap kegiatan inaugurasi.

\section{METODE}

Penelitian ini merupakan studi deskriptif untuk memberikan gambaran tentang partisipasi dan persepsi mahasiswa terhadap kegiatan inaugurasi. Subjek penelitian adalah seluruh mahasiswa FK UMI 
angkatan 2017 dan 2018 yang berpartisipasi pada kegiatan inaugurasi angkatannya dan terhitung masih aktif sebagai mahasiswa FK UMI saat penelitian ini berlangsung. Pengumpulan sampel menggunakan teknik total sampling.

Instrumen yang digunakan untuk mengumpulkan data adalah kuesioner yang telah melalui uji validasi. Kuesioner disusun menggunakan aplikasi "Google Form" dan dikirimkan kepada ketua angkatan 2017 dan 2018. Ketua angkatan kemudian meneruskan link kuesioner ke grup angkatannya masing-masing. Setiap responden mengisi kuesioner sesuai dengan kelowongan waktunya. Penerimaan respon kuesioner ditutup satu pekan setelah kuesioner terakhir dibagikan kepada responden penelitian. Data yang masuk dikumpulkan dan dianalisis menggunakan program microsoft excel dan Statistical Package for Social Sciences (SPSS) serta disajikan dalam bentuk frekuensi dan persentase. Penelitian ini telah mendapatkan rekomendasi persetujuan etik dari Komite Etik Penelitian Kesehatan Universitas Muslim Indonesia dan Rumah Sakit Ibnu Sina Yayasan Wakaf UMI (KEPK UMI dan RSIS YW-UMI) dengan nomor register UMI012007202.

\section{HASIL}

Kuesioner dikirimkan ke grup masing-masing angkatan dengan total partisipan sebanyak 409 orang. Hanya 347 orang responden yang mengembalikan kuesioner. Dari jumlah tersebut, sebanyak 22 orang mengisi kuesioner dengan tidak lengkap sehingga jumlah responden akhir dari penelitian ini adalah 325 orang (response rate $: 79,46 \%$ ).

Pada penelitian ini, kami mengirimkan kuesioner kepada responden yang berisikan pertanyaanpertanyaan seputar persiapan inaugurasi dan bagaimana pendapat mahasiswa tentang dampak kegiatan inaugurasi terhadap proses pembelajaran mahasiswa. Beberapa item yang kami tanyakan antara lain: (1) Identitas responden, (2) Bentuk partisipasi mahasiswa pada kegiatan inaugurasi, (3) Total waktu yang digunakan selama persiapan inaugurasi, (4) Rerata waktu per hari yang digunakan untuk persiapan inaugurasi, (5) Pendapat mahasiswa tentang dampak inaugurasi terhadap konsentrasi dan waktu belajar, serta (6) Pendapat mahasiswa tentang perlu atau tidaknya inaugurasi dilaksanakan.

Hasil penelitian ini didapatkan bahwa mayoritas mahasiswa baru berperan ganda saat persiapan inaugurasi yakni sebagai panitia sekaligus pengisi acara. Hal ini dapat mengarahkan kita pada berbagai kemungkinan, seperti (1) Totalitas mahasiswa untuk menyukseskan acaranya, (2) Kurangnya kemampuan manajerial dalam kepanitiaan, (3) Kurangnya sumber daya manusia, atau (4) Perencanaan acara yang berlebihan tanpa memperhatikan sumber daya yang ada. 
Tabel 1. Bentuk Partisipasi Mahasiswa pada Kegiatan Inaugurasi

\begin{tabular}{ccc}
\hline Bentuk Partisipasi & n & \% \\
\hline Panitia & 81 & 24,9 \\
\hline Pengisi Acara & 58 & 17,8 \\
\hline Panitia dan Pengisi Acara & 186 & 57,2 \\
\hline Total & 325 & 100 \\
\hline & & Sumber : Data primer
\end{tabular}

Tabel 2. Total Waktu yang Digunakan hingga Inaugurasi Berakhir

\begin{tabular}{lcc}
\hline Total Waktu & n & \% \\
\hline $1-2$ bulan & 168 & 51,69 \\
\hline $2-3$ bulan & 82 & 25,23 \\
\hline $3-4$ bulan & 28 & 0,86 \\
\hline$>4$ bulan & 47 & 14,46 \\
\hline Total & 325 & 100 \\
\hline & & Sumber: Data primer
\end{tabular}

Lebih dari 50 persen mahasiswa menggunakan waktu 1-2 bulan mulai dari awal hingga akhir kegiatan inaugurasi. Mahasiswa yang termasuk dalam kelompok ini umumnya hanya berpartisipasi sebagai pengisi acara atau sebagai panitia pendukung yang memang baru diberikan tugas menjelang kegiatan. Selebihnya, terdapat sekitar 25 persen mahasiswa yang menghabiskan waktu 2-3 bulan bahkan hingga lebih dari 4 bulan mulai dari persiapan hingga kegiatan inaugurasi berakhir. Mahasiswa yang termasuk dalam kelompok ini umumnya berpartisipasi sebagai panitia inti yang harus menyusun proposal hingga melaporkan pertanggungjawaban kegiatan kepada yang berwenang.

Tabel 3. Rerata Waktu per Hari yang Digunakan untuk Persiapan Inaugurasi

\begin{tabular}{ccc}
\hline Rerata Waktu per Hari & $\mathbf{n}$ & \% \\
\hline $1-2$ jam & 9 & 2,77 \\
\hline $2-3$ jam & 0 & 0 \\
\hline $3-4$ jam & 82 & 25,23 \\
\hline $4-5$ jam & 0 & 0 \\
\hline $5-6$ jam & 82 & 25,23 \\
\hline$>6$ jam & 152 & 46,77 \\
\hline Total & 325 & 100 \\
\hline & \multicolumn{3}{c}{ Sumber: Data primer }
\end{tabular}

Mayoritas mahasiswa menghabiskan rata-rata lebih dari 6 jam per hari untuk mempersiapkan kegiatan inaugurasi. Kegiatan belajar di FK UMI berlangsung selama 8-9 jam per hari, sejak pukul 8 pagi. Oleh karena itu, persiapan lebih dari 6 jam per hari artinya mahasiswa baru dapat berisitirahat saat pukul 23.00-24.00 dan hanya memiliki waktu istirahat sekitar 5 jam setiap harinya. 
Tabel 4. Apakah Persiapan Inaugurasi Mengganggu Konsentrasi Belajar Anda

\begin{tabular}{ccc}
\hline Konsentrasi Belajar Terganggu & $\mathbf{n}$ & $\boldsymbol{\%}$ \\
\hline Ya & 260 & 80 \\
\hline Tidak & 65 & 20 \\
\hline Total & 325 & 100,0 \\
\hline & \multicolumn{3}{c}{ Sumber: Data primer }
\end{tabular}

Kuantitas dan kualitas tidur merupakan salah satu faktor yang mempengaruhi konsentrasi belajar. Pada kuesioner yang dibagikan, kami menanyakan kepada responden dampak persiapan inaugurasi terhadap konsentrasi belajar dan ternyata 80 persen responden menjawab persiapan inaugurasi mengganggu konsentrasi belajar (Tabel 4). Selain itu, kami juga menanyakan, "Apakah persiapan inaugurasi menyebabkan waktu belajar berkurang?" dan sebanyak 92 persen responden menjawab "Ya" (Tabel 5). Hasil ini tidak mengejutkan mengingat besarnya alokasi waktu yang dicurahkan oleh responden setiap hari untuk persiapan inaugurasi.

Tabel 5. Apakah Persiapan Inaugurasi Menyebabkan Waktu Belajar Anda Berkurang?

\begin{tabular}{ccc}
\hline Waktu Belajar Berkurang & $\mathbf{n}$ & $\mathbf{\%}$ \\
\hline Ya & 299 & 92 \\
\hline Tidak & 26 & 8 \\
\hline Total & 325 & 100,0 \\
\hline & & Sumber: Data primer
\end{tabular}

Tabel 6. Apakah Inaugurasi Perlu Dilaksanakan?

\begin{tabular}{ccc}
\hline Inaugurasi Perlu Dilaksanakan & $\mathbf{n}$ & \% \\
\hline Ya & 261 & 80,3 \\
\hline Tidak & 64 & 19,69 \\
\hline Total & 325 & 100,0 \\
\hline & \multicolumn{3}{c}{ Sumber: Data primer }
\end{tabular}

Satu hal yang menarik pada penelitian ini adalah 80 persen mahasiswa merasa inaugurasi tetap perlu diselenggarakan (Tabel 6) walaupun dampaknya terhadap proses belajar kurang baik. Sebagian besar responden beralasan bahwa inaugurasi diperlukan karena menjadi wadah perkenalan untuk mahasiswa baru. Tempat di mana mereka dapat mengenal teman angkatan dan senior-senior mereka dengan lebih baik. Sebagian responden lagi mengatakan bahwa inaugurasi menjadi tempat mereka mengasah kemampuan manajerial dan melatih kerja sama tim. Di sisi lain, responden yang berpendapat bahwa inaugurasi tidak perlu dilakukan menyebutkan bahwa kegiatan inaugurasi hanya membuang-buang waktu dan tenaga mahasiswa baru padahal mereka harusnya beradaptasi dengan lingkungan yang baru serta belajar dengan tekun. 


\section{PEMBAHASAN}

Menurut Kamus Besar Bahasa Indonesia (KBBI), inaugurasi berarti pengukuhan resmi dalam jabatan atau kedudukan ataupun pelantikan resmi. ${ }^{4}$ Di FK UMI, inaugurasi merupakan puncak dari berbagai kegiatan pengenalan mahasiswa baru (PMB) dan menjadi agenda rutin yang diselenggarakan setiap tahun. Kegiatan ini menjadi penanda masuknya mahasiswa baru dalam Keluarga Besar Mahasiswa Fakultas Kedokteran (KBMFK). Pada kegiatan inaugurasi, mahasiswa baru mempersembahkan lagu, tari, puisi, ataupun bentuk kesenian lainnya kepada para tamu yang berasal dari kalangan orang tua mahasiswa baru, dosen FK UMI, dan mahasiswa senior. Persembahan seni ini dimaksudkan sebagai ajang mahasiswa baru untuk mengekspresikan diri dan melepaskan ketegangan selama perkuliahan. Selain itu, kegiatan inaugurasi ini secara tidak langsung menjadi wadah untuk melatih kerja sama dan membangun kekompakan mahasiswa baru.

Persiapan dan pelaksanaan inaugurasi dilaksanakan pada semester satu. Untuk mempersiapkan penampilannya, mahasiswa baru berlatih selama berjam-jam, selama beberapa minggu. Kegiatan latihan dilakukan sejak sore (setelah perkuliahan selesai) dan berlangsung hingga larut malam. Keesokan paginya, mahasiswa baru kembali mengikuti perkuliahan seperti biasa dan melanjutkan lagi latihan pada sore harinya. Hal ini menyebabkan waktu senggang mahasiswa, yang seharusnya digunakan untuk belajar, mengerjakan tugas, dan berisitirahat, semakin berkurang. Akibatnya, tidak jarang dosen mendapati mahasiswa baru yang tertidur sementara kuliah berlangsung.

Beberapa faktor diketahui berpengaruh terhadap prestasi belajar seperti faktor mahasiswa, faktor guru/ dosen, dan faktor lingkungan. ${ }^{5}$ Faktor mahasiswa meliputi kemampuan/ pengetahuan akademik sebelumnya ${ }^{2,5}$, keterampilan belajar ${ }^{2,5}$, sikap $^{2}$, perilaku dan motivasi ${ }^{2,6}$, kemampuan manajemen waktu ${ }^{2}$, durasi tidur ${ }^{2}$, dan kegiatan ekstrakurikuler ${ }^{7}$. Faktor guru/dosen terkait dengan pendekatan atau teknik yang dilakukan oleh guru/dosen saat berinteraksi dengan mahasiswa ${ }^{5},{ }^{8}$ sedangkan yang termasuk dalam faktor lingkungan adalah karakteristik kurikulum ${ }^{5}$, kondisi penyelenggara pendidikan (sarana prasarana) ${ }^{5,9}$, dan keterlibatan orang tua dalam pendampingan belajar ${ }^{9,10,11}$.

Penelitian ini secara tidak langsung membahas salah satu item dari faktor-faktor yang mempengaruhi capaian belajar, yakni kualitas dan kuantitas tidur. Tidur merupakan proses yang sangat penting bagi anak-anak dan remaja. Beberapa penelitian menunjukkan bahwa kualitas dan kuantitas tidur yang buruk dapat mempengaruhi kemampuan belajar ${ }^{12}$, memori dan konsentrasi ${ }^{3}$, serta performa anak di sekolah $^{12}$. Tidur dikatakan berkualitas jika seseorang bangun dalam kondisi yang segar dan bugar sedangkan kuantitas tidur dikatakan cukup jika seseorang dapat tidur sesuai dengan kebutuhan tidurnya. ${ }^{3}$ 
Hasil penelitian yang dilakukan oleh Fenni at al. $(2016)^{3}$ menunjukkan bahwa mayoritas mahasiswa Fakultas Kedokteran memiliki kualitas tidur yang buruk dan kuantitas tidur yang kurang. Penelitian tersebut juga menemukan bahwa terdapat hubungan yang signifikan antara kualitas dan kuantitas tidur dengan prestasi belajar. ${ }^{3}$ Hasil serupa juga didapatkan dari penelitian Raley et al. (2016). ${ }^{13}$ yang menemukan bahwa mahasiswa dengan indeks prestasi kumulatif (IPK) tinggi memiliki durasi tidur malam yang lebih panjang daripada mahasiswa dengan IPK rendah. Selain itu, mahasiswa dengan IPK tinggi juga memiliki durasi tidur yang sama atau bahkan lebih panjang daripada biasanya pada malam sebelum ujian berlangsung. Hal ini mungkin disebabkan mahasiswa dengan IPK tinggi memiliki manajemen waktu yang baik sehingga mereka mampu menyicil waktu belajar mereka. Di sisi lain, mahasiswa dengan IPK rendah cenderung mengumpulkan waktu belajarnya pada malam sebelum ujian sehingga mereka tidak mendapatkan tidur yang cukup. ${ }^{13}$

Meskipun kami tidak menganalisis hubungan antara kualitas dan kuantitas tidur dengan capaian hasil belajar pada penelitian ini, namun kami menduga bahwa mahasiswa yang menghabiskan waktu lebih dari 6 jam setiap hari untuk persiapan inaugurasi, akan memiliki kuantitas dan kualitas tidur yang buruk. Hal ini akan berdampak negatif terhadap capaian hasil belajar mahasiswa.

Agar tujuan inaugurasi dapat tercapai maksimal, maka diperlukan evaluasi terhadap perencanaan, persiapan, dan pelaksanaan inaugurasi. Data mengenai sumber daya manusia, rencana susunan acara, perlengkapan, sumber pendanaan, serta lokasi dan waktu penyelenggaraan kegiatan harus tersaji dengan lengkap dan terperinci untuk memudahkan proses evaluasi. Masukan dari berbagai pihak, termasuk orang tua, juga diperlukan agar inaugurasi tetap terlaksana dengan baik tanpa mengganggu proses pembelajaran.

\section{KESIMPULAN}

Proses persiapan dan pelaksanaan inaugurasi cukup menyita waktu sehingga mengganggu konsentrasi dan waktu belajar. Walaupun demikian, inaugurasi tetap menjadi komponen penting dalam proses penerimaan mahasiswa baru. Perencanaan kegiatan yang lebih baik mutlak diperlukan agar tujuan pelaksanaan inaugurasi dapat tercapai tanpa memberikan dampak negatif terhadap pembelajaran.

\section{DAFTAR PUSTAKA}

1. Peta Kurikulum Semester Awal FK UMI.

2. Lumley S, Ward P, Roberts L, Mann JP. Self-reported extracurricular activity, academic success, and quality of life in UK medical students. Int J Med Educ. 2015;6:111-117. doi:10.5116/ijme.55f8.5f04

3. Fenny, Supriatmo. Hubungan Kualitas Dan Kuantitas Tidur dengan Prestasi Belajar pada Mahasiswa Fakultas Kedokteran. J Kedokt. 2016;5(3):140-147.

4. Kamus Besar Bahasa Indonesia. https://kbbi.web.id. 
5. Newble D, Cannon R. A Handbook of Medical Teachers 4th Edition. 4th ed.; 2001.

6. Marasabessy N, Prabandari YS, Emilia O, et al. Hubungan Motivasi Berprestasi dan Perhatian terhadap Proses Kognitif pada Mahasiswa Tahun Pertama Jurusan Kesehatan Lingkungan Politeknik Kesehatan Maluku. J Pendidik Kedokt Indones. 2013;2(1):71-78.

7. Correa M, Dumas BK, Jones C, Mbarika V, Ong IM. Extracurricular Activities and Academic Achievement : A Literature Review. 2015;4(9):165-169.

8. Khan KW, Ramzan M, Zia Y, Zafar Y, Khan M, Saeed H. Factors Affecting Academic Performance of Medical Students. Life Sci. 2020;1(1):4. doi:10.37185/lns.1.1.45

9. Singh, Prof S P,Malik, Savita, Singh P. Factors Affecting Academic Performance of Students. Indian J Res. 2016;(April):176-178.

10. Topor DR, Keane SP, Shelton TL, Calkins SD. Parent involvement and student academic performance: A multiple mediational analysis. J Prev Interv Community. 2010;38(3):183-197. doi:10.1080/10852352.2010.486297

11. Mushtaq I, Khan SN. Factors Affecting Students' Academic Performance. Glob J Manag Bus Res Vol. 2012;12(9).

12. Dewald JF, Meijer AM, Oort FJ, Kerkhof GA, Bögels SM. The influence of sleep quality, sleep duration and sleepiness on school performance in children and adolescents: A meta-analytic review. Sleep Med Rev. 2010;14(3):179-189. doi:10.1016/j.smrv.2009.10.004

13. Raley H, Naber J, Cross S, Perlow M. The Impact of Duration of Sleep on Academic Performance in University Students. Madridge J Nurs. 2016;1(1):11-18. doi:10.18689/mjn-1000103 